\title{
Characteristics and Stability of Mercury Vapor Adsorption over Two Kinds of Modified Semicoke
}

\author{
Zhang Huawei, Liu Xiuli, Wang Li, and Liang Peng \\ College of Chemical and Environmental Engineering, Shandong University of Science and Technology, Qingdao, \\ Shandong Province 266510, China \\ Correspondence should be addressed to Zhang Huawei; sdkdzhw@163.com
}

Received 20 June 2014; Accepted 5 August 2014; Published 27 August 2014

Academic Editor: Wenjun Jiang

Copyright (C) 2014 Zhang Huawei et al. This is an open access article distributed under the Creative Commons Attribution License, which permits unrestricted use, distribution, and reproduction in any medium, provided the original work is properly cited.

In an attempt to produce effective and lower price gaseous $\mathrm{Hg}^{0}$ adsorbents, two methods of $\mathrm{HCl}$ and $\mathrm{KMnO}_{4} /$ heat treatment were used respectively for the surface modification of liginite semicoke from inner Mongolia. The different effects of modification process on the surface physical and chemical properties were analyzed. The characteristics and stability of mercury vapor adsorption over two kinds of modified semicoke were investigated. The results indicated that modification process caused lower micropore quantity and volume capacity of semicoke; the $\mathrm{C}-\mathrm{Cl}$ functional groups, $\mathrm{C}=\mathrm{O}$ bond and delocalized electron $\pi$ on the surface of $\mathrm{Cl}$-SC, the amorphous higher valency $\mathrm{Mn}^{x+}$, and $\mathrm{O}=\mathrm{C}-\mathrm{OH}$ functional groups on the surface of $\mathrm{Mn}-\mathrm{H}-\mathrm{SC}$ were the active sites for oxidation and adsorption of gaseous $\mathrm{Hg}^{0}$. Modification process led to higher mercury removal efficiency of semicoke at $140^{\circ} \mathrm{C}$ and reduced the stability of adsorbed mercury of semicoke in simulated water circumstance simultaneously.

\section{Introduction}

Gaseous $\mathrm{Hg}^{0}$ pollutant in flue gas has the properties of being stable, thermodynamic, and insoluble in water, and its removal techniques have become a research focus. At present, one of the most effective ways for gaseous $\mathrm{Hg}^{0}$ removal is injecting varieties of solid adsorbents into flue gas, which can oxidize the elemental mercury into $\mathrm{Hg}^{2+}$ and capture it [1]. Previous research shows that high efficiency gaseous $\mathrm{Hg}^{0}$ adsorbents can be prepared using cheap porous materials by physical and chemical surface modification methods [26]. Lignite semicoke has similar chemical properties with activated carbon, but its price is only one-third of activated carbon or so, which can be widely used as low-cost adsorbent in the fields of flue gas desulfurization and denitrification, oil purification, and wastewater treatment [7-9]. However, there are seldom reports about semicoke as mercury adsorbents of flue gas; the well-developed pore structure and abundant functional groups on the surface of semicoke can provide active sites for the removal of gaseous $\mathrm{Hg}^{0}$ [10]. It is expected to prepare high efficiency and cheap gaseous $\mathrm{Hg}^{0}$ adsorbents by surface modification of lignite semicoke.

For the mercury adsorbed semicoke, it must be disposed as dangerous goods due to its high mercury content and potential toxicity; therefore, the mercury stability on the surface of adsorption product is the major factor which determines its subsequent treatment process. Indeed, in most of coal-fired power plants, the adsorbents injection device is always installed in the upstream of dust cleaning equipment, and the semicoke after mercury adsorption reaction would be captured together with fly ash in the dust cleaning unit. Fly ash is a kind of precious resource and can be used for the preparation of glass ceramics, cement, fertilizer, and sewage purification material $[11,12]$. If the adsorbed mercury on the surface of semicoke is not stable, it will pollute the fly ash product. In the subsequent process of fly ash utilization, the adsorbed mercury is likely to reescape due to the influence of environmental temperature, humidity, and solution $\mathrm{pH}$ value and thus causes secondary pollution on the environment. Therefore, it is necessary to investigate the adsorbed mercury speciation and stability on the semicoke surface and provide reference data for follow-up treatment measure and process for the adsorption product.

\section{Experimental}

2.1. Sample Preparation. The lignite semicoke used in the tests is from the Huolin River of Inner Mongolia; the 
TABLE 1: The BET surface area and pore parameters of semicoke.

\begin{tabular}{|c|c|c|c|c|c|c|c|}
\hline \multirow{2}{*}{ Sample } & \multirow{2}{*}{ BET surface area $\left(\mathrm{m}^{2} / \mathrm{g}\right)$} & \multirow{2}{*}{ Average pore size (nm) } & \multicolumn{3}{|c|}{ Pore volume $\left(\mathrm{m}^{3} / \mathrm{g}\right)$} & \multicolumn{2}{|c|}{ Proportion \% } \\
\hline & & & Total & $\operatorname{Micro}(\leq 2 \mathrm{~nm})$ & Meso & $\operatorname{Micro}(\leq 2 \mathrm{~nm})$ & Meso \\
\hline NM-SC & 84.203 & 2.55 & 0.107 & 0.0775 & 0.0295 & 72.4 & 27.6 \\
\hline Cl-SC & 97.278 & 2.96 & 0.113 & 0.0704 & 0.0426 & 62.3 & 37.7 \\
\hline Mn-H-SC & 65.494 & 3.67 & 0.120 & 0.0602 & 0.0598 & 50.2 & 49.8 \\
\hline
\end{tabular}

preparation method is as follows: we placed a coal sample in a $700^{\circ} \mathrm{C}$ muffle furnace, conducted $1 \mathrm{~h}$ of destructive distillation under anoxic conditions, cooled it to room temperature, and then smashed it to 80 to 100 meshes for use and recorded it as NM-SC; we soaked $10 \mathrm{~g}$ of prepared NMSC for $24 \mathrm{~h}$ into mass fractions $25 \% \mathrm{HCl}$ solution, with a $1: 3$ of solid-liquid ratio; after the reactions were completed, we filtrated and dried the sample, and the semicoke treated with the $\mathrm{HCl}$ may be obtained, which was recorded as $\mathrm{Cl}$ SC; NM-SC was impregnated in a potassium permanganate solution $(0.06 \mathrm{~mol} / \mathrm{L})$, stirred for 4 hour at $90^{\circ} \mathrm{C}$ in a water bath, filtered, and dried, and we took thermal treatment of impregnated sample at $260^{\circ} \mathrm{C}$ under $\mathrm{N}_{2}$ protection for 1.5 hour and recorded it as Mn-H-SC. After the mercury adsorption experiments for $20 \mathrm{~h}$, the samples of $\mathrm{Cl}-\mathrm{SC}$ and $\mathrm{Mn}-\mathrm{H}-\mathrm{SC}$ were named $\mathrm{Hg}-\mathrm{Cl}-\mathrm{SC}$ and $\mathrm{Hg}-\mathrm{Mn}-\mathrm{H}-\mathrm{SC}$.

2.2. Characterization. The physical characterizations of the samples were analyzed by the Brunauer-Emmett-Teller (BET) method, and the surface area and pore size distribution were obtained by adsorbing and desorbing in $\mathrm{N}_{2}$ at $77 \mathrm{~K}$, using an automatic volumetric multipoint apparatus (SSA-4300). Before the measurements were taken, all of the samples were outgassed at $100^{\circ} \mathrm{C}$ for $2 \mathrm{~h}$. The microstructures of the samples were characterized by scanning electron microscopy (KYKY2800B). X-ray photoelectron spectroscopy (Thermo ESCALAB250) with Al K $\alpha(h v=1486.6 \mathrm{eV})$ as the excitation source was used to determine the binding energies of $\mathrm{Cls}$, O1s, Mn2p, and Hg4f. The C1s line at $284.6 \mathrm{eV}$ was taken as a reference for the binding energy calibration.

2.3. Mercury Adsorption Experimental Methodology and Instrumentation. A small fixed bed reactor described in [4] was employed to evaluate the gaseous $\mathrm{Hg}^{0}$ removal efficiency of semicoke under the simulated flue gas condition. The adsorption efficiency was calculated as follows:

$$
\eta=1-\frac{C_{t}}{C_{0}},
$$

where $\eta$ indicates adsorption efficiency, $C_{0}$ is the initial concentration of gaseous $\mathrm{Hg}^{0}$, and $C_{t}$ indicates the concentration of gaseous $\mathrm{Hg}^{0}$ after adsorption. The mercury volume quantity in unit mass of adsorbent was calculated as follows:

$$
q=\frac{C_{0} L t-\int_{0}^{t} C L d t}{m},
$$

where $q$ represents mercury volume quantity in unit mass of adsorbent, $L$ is the gas flow, $t$ is the adsorption time, and $m$ is the dosage of adsorbent.
Mercury concentration in flue gas was measured online by QM201 mercury analyzer, in which detection range is from 0 to $50 \mu \mathrm{g} / \mathrm{m}^{3}$, and mercury concentration in leaching solution was measured by SG-921 mercury analyzer, in which detection range is from 0.1 to $10 \mathrm{ng} / \mathrm{mL}$.

2.4. The Toxicity Characteristic Leaching Procedure and Sequential Chemical Extraction Experiments of Adsorption Products. The toxicity characteristic leaching procedure (TCLP) tests are carried out according to the methods in [13]; we weighed $0.5 \mathrm{~g}$ adsorption sample accurately, put it in glacial acetic acid solution whose $\mathrm{pH}$ value is 4.93 , where the mass ratio of solid to liquid is $1: 20$, impregnated it for $20 \mathrm{~h}$, and determined the mercury concentration in the supernatant. The details of sequential chemical extraction experiments are given in $[14,15]$; the semicoke samples of adsorption products were extracted using the following solutions: (1) $1 \mathrm{~mol} / \mathrm{L}$ $\mathrm{MgCl}_{2}$, (2) $10 \mathrm{~mol} / \mathrm{L} \mathrm{HCI}$, (3) $2 \mathrm{~mol} / \mathrm{L} \mathrm{HNO}_{3}$, (4) $50 \mathrm{~g} / \mathrm{L}$ $\mathrm{Na}_{2} \mathrm{~S}$ in $10 \mathrm{~g} / \mathrm{L} \mathrm{NaOH}$, and (5) aqua regia. The corresponding mercury forms in extraction for each step are as follows: (1) water soluble, (2) exchangeable, (3) hydrochloric acid soluble, (4) nitric acid soluble, and (5) mercuric sulfide and residual mercury.

\section{Results and Discussion}

3.1. Analysis of Specific Surface Area and Pore Structure. From the data shown in Table 1, the specific surface area and pore structure analysis of three kinds of semicoke, it can be seen that the surface area and total pore volume were slightly increased after $\mathrm{HCl}$ treatment; this is because $\mathrm{HCl}$ can react with ash in semicoke and produce soluble chloride; part of channels blocked by ash are got through in the following washing process and cause the surface area and total pore volume to increase. However, the HCI treatment only increased the volumes of the mesopores and macropores; in the meantime, it also gave rise to the partial transition of the micropores to mesopores and macropores; this conclusion is consistent with previous research of Dubinin [16] and Yanxu et al. [17]. After $\mathrm{KMnO}_{4} /$ heat treatment, the specific surface area of semicoke decreased, the proportion and volume of micropores obviously reduced, and the average pore size increased, which indicated that part of micropore structures were destroyed during the $\mathrm{KMnO}_{4}$ /heat treatment process.

3.2. Analysis of Scanning Electron Microscopy (SEM). Figure 1 describes the surface microtopography of NM-SC, Cl$\mathrm{SC}$, and Mn-H-SC. It can be seen that the surface of crude semicoke is flat, and the pores on the sample have 


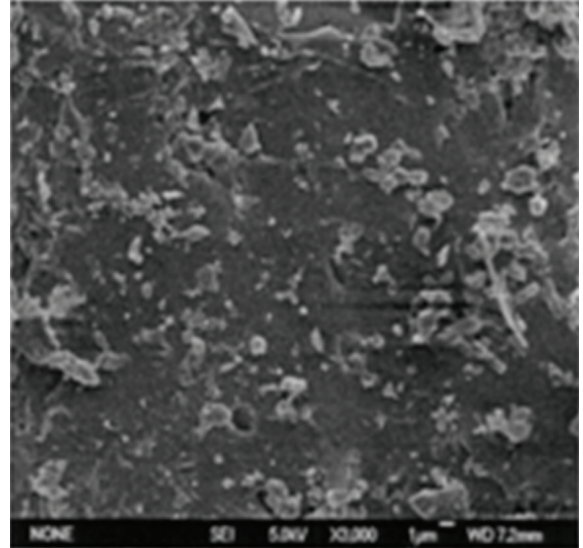

(a) NM-SC

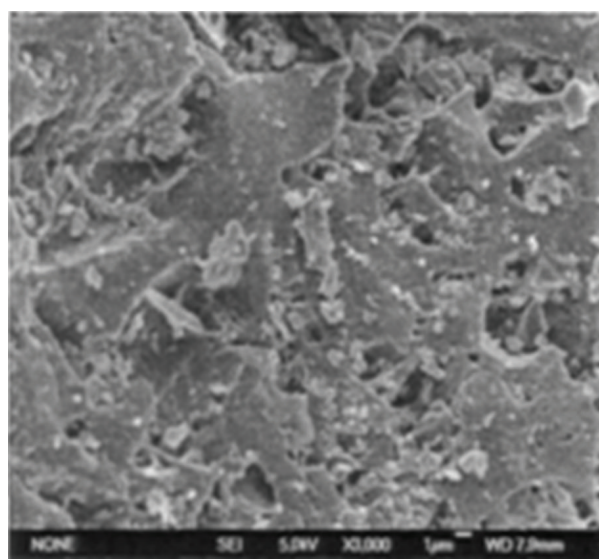

(b) $\mathrm{Cl}-\mathrm{SC}$

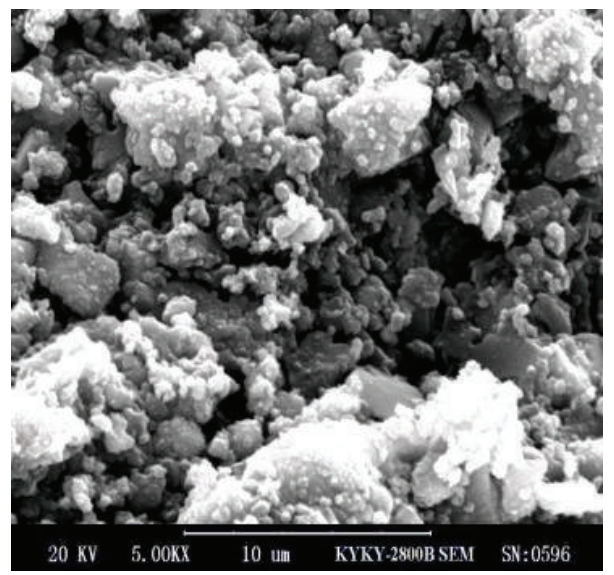

(c) Mn-H-SC

FIgURE 1: SEM images of NM-SC, Cl-SC, and Mn-H-SC.

the properties of uneven size and irregular shape. HCI treatment did not destroy the pore structure of crude semicoke but clearly generated many new pores with different sizes. After $\mathrm{KMnO}_{4}$ /heat treatment, the surface of $\mathrm{Mn}-\mathrm{H}$-SC was covered by a layer of attachment; parts of pores were blocked up and caused the surface roughness of the samples to increase significantly.

3.3. Analysis of X-Ray Photoelectron Spectroscopy (XPS). Xray photoelectron spectroscopy (XPS) was applied to analyze the surface oxygenic functional groups of three kinds of adsorbents (NM-SC, Cl-SC, and Mn-H-SC), two kinds of adsorbents with captured gaseous $\mathrm{Hg}^{0}$ ( $\mathrm{Hg}-\mathrm{Cl}-\mathrm{SC}$ and $\mathrm{Hg}-$ $\mathrm{Mn}-\mathrm{H}-\mathrm{SC}$ ), and valence state of manganese oxide of two samples (Mn-H-SC and Hg-Mn-H-SC). The narrow region spectrum of C1s and $\mathrm{Mn} 2 \mathrm{p}_{3 / 2}$ was fitted by multipeaks using XPS Peak Processing software. The fitting parameters of C1s are C-C-C (284.0 285.1 eV), C-OR (285.3 287.0 eV), C=O $(286.8 \sim 288.1 \mathrm{eV})$, and $\mathrm{O}=\mathrm{C}-\mathrm{OH}(288.1 \sim 290.0 \mathrm{eV})[18]$, and those of $\mathrm{Mn} 2 \mathrm{p}_{3 / 2}$ are $\mathrm{Mn}^{7+}(645.6 \mathrm{eV}), \mathrm{Mn}^{6+}(644.2 \mathrm{eV})$, $\mathrm{Mn}^{4+}(643.0 \mathrm{eV}), \mathrm{Mn}^{3+}(642.1 \mathrm{eV})$, and $\mathrm{Mn}^{2+}(641.0 \mathrm{eV})[19$, $20]$.

According to the fitting results of $\mathrm{Cls}$ spectrum shown in Table 2, it may be concluded that $\mathrm{C}-\mathrm{C}$ carbon species
TABLE 2: Surface carbon functional groups distribution of NM-SC, $\mathrm{Cl}-\mathrm{SC}$, and $\mathrm{Mn}-\mathrm{H}-\mathrm{SC}$.

\begin{tabular}{lcccc}
\hline Sample & C-C (\%) & C-OR (\%) & C=O (\%) & O=C-OH (\%) \\
\hline SC & 51.37 & 34.32 & 9.48 & 4.83 \\
Cl-SC & 66.96 & 12.79 & 11.22 & 9.03 \\
Mn-H-SC & 75.17 & 13.40 & 4.56 & 6.87 \\
Hg-Cl-SC & 77.18 & 12.69 & 5.98 & 4.15 \\
Hg-Mn-H-SC & 77.83 & 14.68 & 3.21 & 4.28 \\
\hline
\end{tabular}

are the main carbon components on the surface of SC (51.37\%), followed by the carbon species C-OR (34.32\%), $\mathrm{C}=\mathrm{O}(9.48 \%)$, and $\mathrm{O}=\mathrm{C}-\mathrm{OH}(4.83 \%) . \mathrm{HCl}$ modification increased the carbon species of $\mathrm{C}-\mathrm{C}, \mathrm{C}=\mathrm{O}$, and $\mathrm{O}=\mathrm{C}-$ $\mathrm{OH}$ by $15.59 \%, 1.74 \%$, and $4.20 \%$, respectively, and reduced the carbon species of C-OR by $21.53 \%$. After $\mathrm{KMnO}_{4} /$ heat treatment, the carbon species of $\mathrm{C}-\mathrm{C}$ and $\mathrm{O}=\mathrm{C}-\mathrm{OH}$ on semicoke increased by $23.80 \%$ and $2.04 \%$ and $\mathrm{C}-\mathrm{OR}$ and $\mathrm{C}=\mathrm{O}$ decreased by $20.92 \%$ and $4.92 \%$, respectively. In general, two kinds of modification methods can increase graphitization degree, the content of carboxylic acid and ester chemical functional groups of semicoke. $\mathrm{HCl}$ treatment also increased the content of alcohols, ethers, ketones, quinones, 
TABLE 3: Distribution of surface Mn ions of Mn-H-SC, and Hg-Mn-H-SC.

\begin{tabular}{lcccccc}
\hline Sample & $\mathrm{Mn}^{7+}(\%)$ & $\mathrm{Mn}^{6+}(\%)$ & $\mathrm{Mn}^{4+}(\%)$ & $\mathrm{Mn}^{3+}(\%)$ & $\mathrm{Mn}^{2+}(\%)$ & $\mathrm{Mn} \mathrm{AOS}^{2}$ \\
\hline Mn-H-SC & 0.00 & 10.62 & 35.59 & 32.57 & 3.46 \\
Hg-Mn-H-SC & 0.00 & 0.00 & 32.02 & 44.10 & 22.88 & 3.08 \\
\hline
\end{tabular}

AOS: average oxidation state.

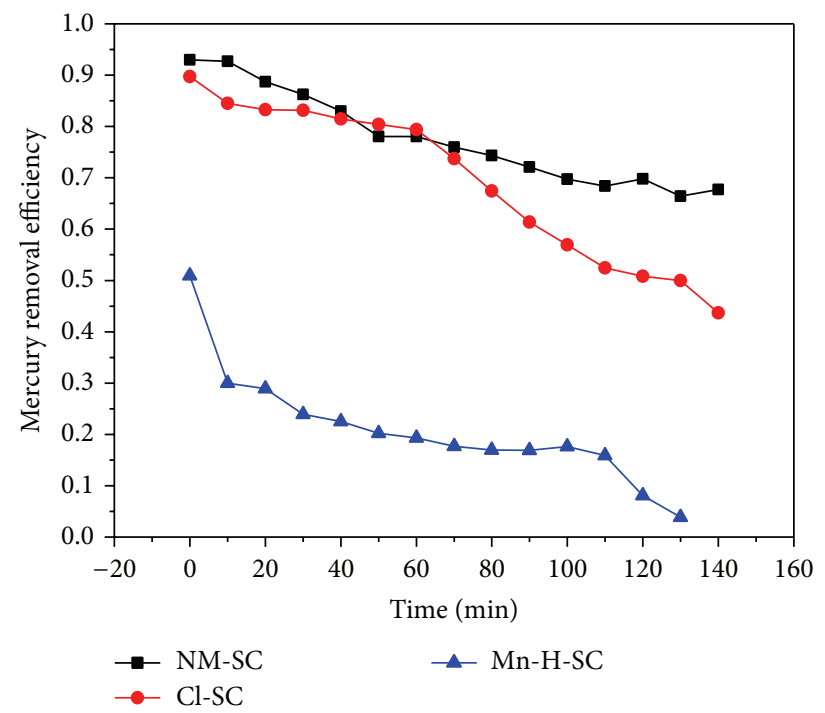

(a) $30^{\circ} \mathrm{C}$

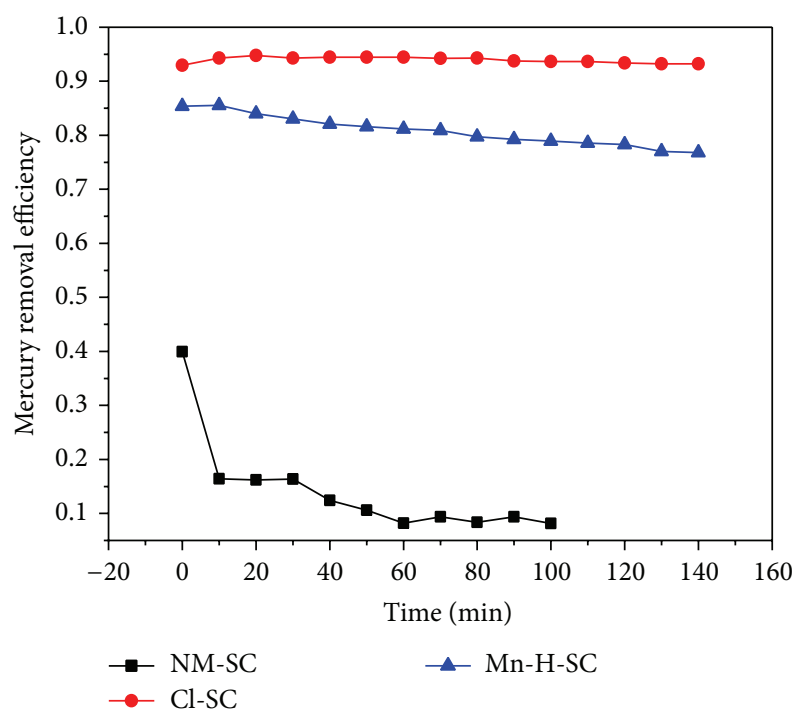

(b) $140^{\circ} \mathrm{C}$

Figure 2: Mercury removal efficiency of NM-SC, Cl-SC, and Mn-H-SC at $30^{\circ} \mathrm{C}$ and $140^{\circ} \mathrm{C}$.

and other chemical functional groups, and $\mathrm{KMnO}_{4} /$ heat treatment reduced the content of those functional groups. For Cl-SC and Mn-H-SC samples, surface graphite carbon content increased slightly after gaseous $\mathrm{Hg}^{0}$ adsorption, while the carbon content of carbonyl or quinone functional groups and carboxyl or ester functional groups decreased slightly; it is probably due to the fact that, in the gaseous $\mathrm{Hg}^{0}$ adsorption process, part of $\mathrm{C}=\mathrm{O}$ groups of ketones, quinones, carboxylic acids, and esters oxidized gaseous $\mathrm{Hg}^{0}$ and at the same time it was reduced, causing the $\mathrm{C}=\mathrm{O}$ double bond to be broken, thus resulting in the decrease of carbonyl or quinone functional groups and carboxyl or ester functional groups of semicoke.

The $\mathrm{Mn} 2 \mathrm{p}_{3 / 2}$ multipeak fitting results of $\mathrm{Mn}-\mathrm{H}-\mathrm{SC}$ and its adsorption product are shown in Table 3. It can be seen that the average oxidation degree of manganese on the surface of $\mathrm{Mn}-\mathrm{SC}$ is 3.46; there is no $\mathrm{Mn}^{7+}$ compounds. These results indicated that the potassium permanganate decomposed during the modification, and a portion was reduced to a lower valence state by the surface organic functional groups or carbon atoms of semicoke [21, 22]. After gaseous $\mathrm{Hg}^{0}$ adsorption at $140^{\circ} \mathrm{C}$, compared with $\mathrm{Mn}-\mathrm{H}-\mathrm{SC}$, the average manganese oxidation state on $\mathrm{Hg}-\mathrm{Mn}-\mathrm{H}-\mathrm{SC}$ surface reduced by $0.38, \mathrm{Mn}^{7+}$ spectrum peak disappeared, the atomic ratio of $\mathrm{Mn}^{4+}$ decreased slightly, and the atomic ratio of $\mathrm{Mn}^{3+}$ and $\mathrm{Mn}^{2+}$ rose sharply. This showed that $\mathrm{Mn}^{6+}$ and $\mathrm{Mn}^{4+}$ on the surface of $\mathrm{Mn}-\mathrm{H}-\mathrm{SC}$ would oxidize gaseous $\mathrm{Hg}^{0}$ to $\mathrm{Hg}^{2+}$ in adsorption process and were reduced to their lower valence state, $\mathrm{Mn}^{3+}$ and $\mathrm{Mn}^{2+}$.

3.4. Gaseous $\mathrm{Hg}^{0}$ Adsorption Characteristics of Semicoke. In Figure 2, under the conditions that the inlet mercury concentration is $30 \mu \mathrm{g} / \mathrm{m}^{3}$, gas flow is $1 \mathrm{~L} / \mathrm{min}$, adsorbent is $0.50 \mathrm{~g}$, and adsorbent temperature is $30^{\circ} \mathrm{C}$ and $140^{\circ} \mathrm{C}$, the gaseous $\mathrm{Hg}^{0}$ removal efficiency of NM-SC, Cl-SC, and Mn$\mathrm{H}-\mathrm{SC}$ is described in Figure 2.

It is observed that when the adsorption temperature is $30^{\circ} \mathrm{C}, \mathrm{NM}-\mathrm{SC}$ has a good mercury removal performance. At low temperature, gaseous $\mathrm{Hg}^{0}$ takes physical adsorption as the primary reaction on the semicoke surface; the gaseous $\mathrm{Hg}^{0}$ is primarily absorbed in the micropores, and the surface area and pore structure of semicoke are the principal factors that determine the mercury removal performance. The analysis data of the specific surface area and pore structure showed that the crude semicoke had a relatively large specific surface area and pore volume, and the surface micropore proportion reached to $72.4 \%$; the average pore diameter was $2.55 \mathrm{~nm}$; thus it has high mercury removal efficiency. The BET analysis data showed that although $\mathrm{HCl}$ treatment increased the total pore volume and surface area of semicoke slightly, the proportion and volume of micropore declined and the physical adsorption capacity of semicoke to gaseous $\mathrm{Hg}^{0}$ reduced to a certain extent, thereby leading to $\mathrm{Cl}-\mathrm{SC}$ that presented lower mercury removal efficiency. $\mathrm{KMnO}_{4} /$ heat 
treatment decreased mercury removal efficiency of semicoke at $30^{\circ} \mathrm{C}$ obviously; it is due to the fact that a portion of pores on semicoke surface is clogged by attachments after modification process, and heat treatment at $260^{\circ} \mathrm{C}$ causes partial collapse of micropores, which led to part transition of micropores to mesopores, so the micropore portion and volume of Mn-H-SC were significantly lower than NM-SC and performed poor mercury removal performance at $30^{\circ} \mathrm{C}$.

When the adsorption temperature is $140^{\circ} \mathrm{C}$, the mercury removal efficiency of $\mathrm{Cl}-\mathrm{SC}$ was much higher than that of NM-SC and was maintained above $90 \%$ after $140 \mathrm{~min}$ adsorption reaction. Gaseous $\mathrm{Hg}^{0}$ mainly takes chemical adsorption on semicoke surface at high temperature; $\mathrm{HCl}$ treatment has great influence on surface chemical properties of semicoke, mainly to increase the contents of the functional groups such as carboxyl and the phenolic hydroxyl groups, and in the modification process, the $\mathrm{Cl}^{-}$in hydrochloric acid solutioncantake ion-exchange reaction on the semicoke surface, thus enabling part of chlorine elements to be absorbed on the semicoke surface and forming the $\mathrm{Cl}-\mathrm{C}-\mathrm{Cl}$ functional groups. When the concentration of the $\mathrm{Cl}^{-}$on the semicoke surface is high, the gaseous $\mathrm{Hg}^{0}$ can react with $\mathrm{Cl}^{-}$ and produce mercury chlorides, such as $[\mathrm{HgCl}]^{+}, \mathrm{HgCl}_{2}$, or $\left[\mathrm{HgCl}_{4}\right]^{2-}[23,24]$. The $\mathrm{C}=\mathrm{O}$ bond and delocalized electron $\pi$ on the semicoke surface also may be taken as electron acceptors, thus enabling the reaction between $\mathrm{Hg}^{0}$ and $\mathrm{Cl}^{-}$to be conducted towards the positive direction and generating the stable chloride of mercury. Both the oxygen-containing functional groups and chlorine-containing groups on Cl-SC surface can provide active sites for gaseous $\mathrm{Hg}^{0}$ oxidation and chemical adsorption, thus remarkably increasing the mercury removal efficiency of $\mathrm{Cl}-\mathrm{SC}$ at $140^{\circ} \mathrm{C}$. The mercury removal efficiency of Mn-H-SC was slightly lower than Cl-SC but significantly higher than NM-SC. $\mathrm{KMnO}_{4} /$ heat treatment modification can increase the content of $\mathrm{O}=\mathrm{C}-\mathrm{OH}$ groups in carboxyl and ester groups on semicoke surface and generate the amorphous $\mathrm{MnO}_{x}$ compounds with higher valence; the average oxidization degree of manganese is 3.46. Gaseous $\mathrm{Hg}^{0}$ can be oxidized to $\mathrm{Hg}^{2+}$ by high valence $\mathrm{Mn}^{x+}$ and $\mathrm{O}=\mathrm{C}-\mathrm{OH}$ functional groups and chemically adsorbed in the pore channels of Mn-H-SC, making the mercury removal performance improve significantly.

3.5. Mercury Speciation and Stability on the Surface of Semicoke. For adsorption products, the adsorbed mercury stability in simulated water environment was investigated using TCLP leaching tests, and the mercury speciation on the surface of semicokes was studied using sequential chemical extraction experiments.

The TCLP leaching experiment results of three kinds of semicoke samples are shown in Table 4. It can be seen from the TCLP tests data that the mercury stability of semicoke samples after adsorption reaction has great relationship on the adsorption temperatures and modification methods of semicoke. For the samples of $30^{\circ} \mathrm{C}$ mercury adsorption products, no mercury was detected in the leachate of NMSC samples; mercury concentrations in the leachate of Cl-SC and $\mathrm{Mn}-\mathrm{H}-\mathrm{SC}$ were $7.6 \mu \mathrm{g} / \mathrm{L}$ and $9.0 \mu \mathrm{g} / \mathrm{L}$, respectively, which
TABLE 4: TCLP experiment results of three kinds of semicoke.

\begin{tabular}{lcccccc}
\hline \multirow{2}{*}{ Sample } & \multicolumn{2}{c}{$\mathrm{NM}-\mathrm{SC}$} & \multicolumn{2}{c}{$\mathrm{Cl}-\mathrm{SC}$} & \multicolumn{2}{c}{$\mathrm{Mn}-\mathrm{H}-\mathrm{SC}$} \\
& $30^{\circ} \mathrm{C}$ & $140^{\circ} \mathrm{C}$ & $30^{\circ} \mathrm{C}$ & $140^{\circ} \mathrm{C}$ & $30^{\circ} \mathrm{C}$ & $140^{\circ} \mathrm{C}$ \\
\hline$\mu \mathrm{g} / \mathrm{L}$ & $\mathrm{BDL}$ & 0.18 & 7.6 & 168.2 & 9.0 & 3.3 \\
\hline
\end{tabular}

BDL: below detection limitation.

are lower than the safe concentration of TCLP standard value of $25 \mu \mathrm{g} / \mathrm{L}$. The stability of adsorbed mercury in micropores of semicoke is relativity better at low temperatures and is not easy to escape in the leaching process. The micropore proportion of Cl-SC and $\mathrm{Mn}-\mathrm{H}-\mathrm{SC}$ samples is lower than that of NM-SC, so causing the mercury stability on the surface of semicoke to somewhat decrease. For the samples of $140^{\circ} \mathrm{C}$ mercury adsorption products, the mercury concentration in the filtrate of Cl-SC sample was the highest and reached $168.2 \mu \mathrm{g} / \mathrm{L}$; the mercury concentration in the filtrate of Mn$\mathrm{H}$-SC sample was higher than that of NM-SC. At higher adsorption temperature, gaseous $\mathrm{Hg}^{0}$ can be oxidized to $\mathrm{HgCl}_{2}$ and $\mathrm{HgO}$, respectively, on the surface of $\mathrm{Cl}-\mathrm{SC}$ and $\mathrm{Mn}-\mathrm{H}-\mathrm{SC}$. The solubility of elemental mercury, $\mathrm{HgO}$, and $\mathrm{HgCl}_{2}$ is $0.06,53$, and $6.9 \times 10^{4} \mathrm{mg} / \mathrm{L}$, respectively; $\mathrm{HgCl}_{2}$ is easily soluble in water, which makes the mercury concentration in the filtrate of Cl-SC sample significantly high; $\mathrm{HgO}$ has lower solubility in water, so the mercury concentration in the filtrate of Mn-H-SC sample is below the safety standard value. In short, the modification process improved the mercury removal performance of semicoke at high temperatures but in different extent reduced the stability of adsorbed mercury on the surface of semicoke in simulated water environment.

The sequential chemical extraction experiment results of semicoke adsorption products are shown in Table 5. The experiment error of total mercury content is less than $10 \%$, which indicated the reliability of the sequential chemical extraction. In the sequential extraction process, the extract of the first step is water soluble mercury; the exchangeable mercury of the second step mainly refers to the organic mercury which is instable on the surface of semicoke; the hydrochloric acid dissolved mercury of the third step means the $\mathrm{HgO}$ generated by the reaction of gaseous $\mathrm{Hg}^{0}$ and active oxidization in semicoke such as manganese oxides $\mathrm{MnO}_{x}$ and amorphous and crystalline $\mathrm{Fe}, \mathrm{Al}$ oxides; the nitrate dissolved mercury of the fourth step refers to the elemental mercury adsorbed on the semicoke surface; the extract of the fifth and sixth steps is $\mathrm{HgS}$ and residual mercury, respectively $[15,25]$. For the mercury adsorption products of NM-SC, Cl$\mathrm{SC}$, and $\mathrm{Mn}-\mathrm{H}-\mathrm{SC}$ at $30^{\circ} \mathrm{C}$ and $140^{\circ} \mathrm{C}$, the content of $\mathrm{HgS}$ and residual mercury was about $10 \%$, which may be $\mathrm{HgS}$ partially contained in semicoke itself or the stable forms of mercury generated in the reaction of gaseous $\mathrm{Hg}^{0}$ and sulfur or nitrogen element in semicoke.

Water soluble and exchangeable mercury were not detected in the extract of NM-SC adsorption product at $30^{\circ} \mathrm{C}$, and $2.8 \%$ of hydrochloric acid solution mercury were detected, which is the $\mathrm{HgO}$ generated in the reaction of gaseous $\mathrm{Hg}^{0}$ and oxygen-containing functional groups or the amorphous and crystalline $\mathrm{Fe}, \mathrm{Al}$ oxides in semicoke; the 
TABLE 5: Sequential extraction procedure results of semicoke adsorption products.

\begin{tabular}{|c|c|c|c|c|c|c|c|}
\hline Sample & Water soluble (\%) & Exchangeable (\%) & $\mathrm{HCl}$ soluble (\%) & $\mathrm{HNO}_{3}$ soluble (\%) & $\operatorname{HgS}(\%)$ & Residual (\%) & Total (\%) \\
\hline \multicolumn{8}{|l|}{ NM-SC } \\
\hline $30^{\circ} \mathrm{C}$ & 0 & 0 & 2.8 & 86.9 & 3.2 & 5.7 & 98.6 \\
\hline $140^{\circ} \mathrm{C}$ & 0 & 1.1 & 24.9 & 61.6 & 5.3 & 4.9 & 97.8 \\
\hline \multicolumn{8}{|l|}{ Cl-SC } \\
\hline $30^{\circ} \mathrm{C}$ & 0.9 & 2.6 & 6.5 & 79.7 & 4.8 & 3.9 & 98.4 \\
\hline $140^{\circ} \mathrm{C}$ & 64.4 & 13.2 & 15.1 & 2.7 & 3.6 & 3.3 & 102.3 \\
\hline \multicolumn{8}{|l|}{ Mn-H-SC } \\
\hline $30^{\circ} \mathrm{C}$ & 0 & 1.7 & 5.9 & 79.1 & 5.4 & 4.3 & 96.4 \\
\hline $140^{\circ} \mathrm{C}$ & 3.8 & 6.4 & 67.2 & 15.3 & 5.1 & 4.8 & 102.6 \\
\hline
\end{tabular}

content of nitrate soluble mercury is as high as $89.6 \%$, which is mainly the elemental mercury physical adsorbed on the semicoke surface. For the extract of NM-SC adsorption product at $140^{\circ} \mathrm{C}$, hydrochloric acid soluble mercury content increased to $24.9 \%$ and nitric acid soluble mercury content reduced to $61.6 \%$, indicating that the content of $\mathrm{HgO}$ increased, while the content of elemental mercury decreased in the sample of NMSC adsorption product at high temperatures.

It could detect $79.7 \%$ of elemental mercury in the extract of $\mathrm{Cl}-\mathrm{SC}$ adsorption product at $30^{\circ} \mathrm{C}$ and also contained a small amount of oxidation states and unstable organic mercury. For the adsorption product of $140^{\circ} \mathrm{C}$, mercury mainly exists in water soluble form, and its content is $64.4 \%$; this is because the gaseous $\mathrm{Hg}^{0}$ can take reaction with $\mathrm{Cl}$ element of semicoke and generate $\mathrm{HgCl}_{2}$ with high solubility. There was also part of exchangeable and acid soluble mercury on Cl-SC, mainly referring to unstable organic mercury or $\mathrm{HgO}$ generated in the reaction of gaseous $\mathrm{Hg}^{0}$ with surface oxygen-containing groups such as carboxyl, lactone, and hydroxyl.

The main mercury form of Mn-H-SC adsorption products at $30^{\circ} \mathrm{C}$ and $140^{\circ} \mathrm{C}$ was elemental and $\mathrm{HgO}$, respectively.

\section{Conclusions}

(1) Hydrochloric acid treatment mainly increased the volume of mesopores and macropores of semicoke and the content of chemical functional groups such as alcohols, ethers, ketones, and quinines on the semicoke surface. $\mathrm{KMnO}_{4}$ /heat treatment combination modification process caused a decrease of micropore proportion on the semicoke surface, increased the graphitization degree and the content of carboxylic acid or ester chemical functional groups, and reduced the chemical functional groups content of alcohols, ethers, ketones, and quinines.

(2) Gaseous $\mathrm{Hg}^{0}$ mainly took physical adsorption on the surface of semicoke at low temperature, while chemical adsorption was the main mechanism at high temperature; the $\mathrm{Cl}-\mathrm{C}-\mathrm{Cl}$ functional groups, $\mathrm{C}=\mathrm{O}$ bonds and delocalized electrons $\pi$ of $\mathrm{Cl}-\mathrm{SC}$, and the high valence $\mathrm{Mn}^{x+}$ and $\mathrm{O}=\mathrm{C}-\mathrm{OH}$ functional groups of $\mathrm{Mn}-\mathrm{H}-\mathrm{SC}$ could be taken as electron acceptors, made gaseous $\mathrm{Hg}^{0}$ oxidize to $\mathrm{Hg}^{2+}$, and chemically adsorbed in the pore channel of semicoke, thus improving the mercury removal efficiency of semicoke obviously.

(3) The TCLP leaching experiment results indicated that the modification process could improve the mercury removal performance of semicoke at high temperatures but in different extent reduced the stability of adsorbed mercury on the surface of semicoke in simulated water environment. The contents of elemental mercury were the highest in three samples after $30^{\circ} \mathrm{C}$ adsorption, and the major adsorbed mercury forms of NM-SC, Mn-H-SC, and Cl-SC after $140^{\circ} \mathrm{C}$ adsorption were elemental $\mathrm{HgO}$ and $\mathrm{HgCl}_{2}$, respectively.

\section{Conflict of Interests}

The authors declare that there is no conflict of interests regarding the publication of this paper.

\section{Acknowledgments}

This study was supported by the National Natural Science Foundation of China (nos. 21006059 and 21276416), the Foundation of State Key Laboratory of Mining Disaster Prevention and Control Cofounded by Shandong Province and the Ministry of Science and Technology, and the Graduate Science and Technology Innovation Fund (YC140215).

\section{References}

[1] H. Yang, Z. Xu, M. Fan, A. E. Bland, and R. R. Judkins, "Adsorbents for capturing mercury in coal-fired boiler flue gas," Journal of Hazardous Materials, vol. 146, no. 1-2, pp. 1-11, 2007.

[2] S. H. Lee, Y. J. Rhim, S. P. Cho, and J. I. Baek, "Carbon-based novel sorbent for removing gas-phase mercury," Fuel, vol. 85, no. 2, pp. 219-226, 2006.

[3] P. Zhao, X. Guo, and C. Zheng, "Removal of elemental mercury by iodine-modified rice husk ash sorbents," Journal of Environmental Sciences, vol. 22, no. 10, pp. 1629-1636, 2010.

[4] H. Zhang, J. Chen, P. Liang, and L. Wang, "Mercury oxidation and adsorption characteristics of potassium permanganate modified lignite semi-coke," Journal of Environmental Sciences, vol. 24, no. 12, pp. 2083-2090, 2012. 
[5] Y. Wang and Y. Duan, "Effect of manganese ions on the structure of $\mathrm{Ca}(\mathrm{OH})_{2}$ and mercury adsorption performance of $\mathrm{Mn}^{x+} / \mathrm{Ca}(\mathrm{OH})_{2}$ composites," Energy and Fuels, vol. 25, no. 4, pp. 1553-1558, 2011.

[6] J. M. Gatica and H. Vidal, "Non-cordierite clay-based structured materials for environmental applications," Journal of Hazardous Materials, vol. 181, no. 1-3, pp. 9-18, 2010.

[7] X. R. Zheng, W. R. Bao, Q. M. Jin et al., "Impact of impregnation pressure on desulfurization performance of $\mathrm{Zn}$-based sorbents on semi-coke," Journal of Natural Gas Chemistry, vol. 21, no. 1, pp. 56-60, 2012.

[8] J. P. Wang, Z. Yan, L. L. Liu et al., "Low-temperature SCR of NO with $\mathrm{NH}_{3}$ over activated semi-coke composite-supported rare earth oxides," Applied Surface Science, vol. 309, no. 1, pp. 1-10, 2014.

[9] P. Parastoo, A. Alla, K. Kambiz et al., "Removal of organic compounds and trace metals from oil sands process-affected water using zero valent iron enhanced by petroleum coke," Journal of Environmental Management, vol. 139, no. 15, pp. 50$58,2014$.

[10] W. H. Zhang, X. Liu L, and L. Wang, "Mercury adsorption form and stability on the surface of lignite semi-coke," Journal of China Coal Society, vol. 39, no. 4, pp. 776-781, 2014.

[11] Y. Zhao, J. Zhang, C. Tian, H. Li, X. Shao, and C. Zheng, "Mineralogy and chemical composition of high-calcium fly ashes and density fractions from a coal-fired power plant in China," Energy and Fuels, vol. 24, no. 2, pp. 834-843, 2010.

[12] C. Cao, T. Peng, and W. Ding, "Effect of crystallization temperature on crystallization and properties of $\mathrm{CaO}-\mathrm{Al}_{2} \mathrm{O}_{3}-\mathrm{SiO}_{2}-$ $\mathrm{Fe}_{2} \mathrm{O}_{3}$ glass ceramics from coal fly ash," Journal of the Chinese Ceramic Society, vol. 41, no. 1, pp. 122-128, 2013.

[13] Z. Luo, C. Hu, J. Zhou, and K. Cen, "Stability of mercury on three activated carbon sorbents," Fuel Processing Technology, vol. 87, no. 8, pp. 679-685, 2006.

[14] J. W. Graydon, X. Zhang, D. W. Kirk, and C. Q. Jia, "Sorption and stability of mercury on activated carbon for emission control," Journal of Hazardous Materials, vol. 168, no. 2-3, pp. 978-982, 2009.

[15] C. Sladek and M. S. Gustin, "Evaluation of sequential and selective extraction methods for determination of mercury speciation and mobility in mine waste," Applied Geochemistry, vol. 18, no. 4, pp. 567-576, 2003.

[16] M. M. Dubinin, "Fundamentals of the theory of adsorption in micropores of carbon adsorbents: characteristics of their adsorption properties and microporous structures," Carbon, vol. 27, no. 3, pp. 457-467, 1989.

[17] L. Yanxu, C. Jiangyao, and S. Yinghuang, "Adsorption of multicomponent volatile organic compounds on semi-coke," Carbon, vol. 46, no. 6, pp. 858-863, 2008.

[18] U. Zielke, K. J. Hüttinger, and W. P. Hoffman, "Surface-oxidized carbon fibers: I. Surface structure and chemistry," Carbon, vol. 34, no. 8, pp. 983-998, 1996.

[19] M. Oku, "X-ray photoelectron spectra of $\mathrm{KMnO}_{4}$ and $\mathrm{K}_{2} \mathrm{MnO}_{4}$ fractured in situ," Journal of Electron Spectroscopy and Related Phenomena, vol. 74, no. 2, pp. 135-148, 1995.

[20] H. W. Nesbitt and D. Banerjee, "Interpretation of XPS Mn(2p) spectra of $\mathrm{Mn}$ oxyhydroxides and constraints on the mechanism of $\mathrm{MnO}_{2}$ precipitation," American Mineralogist, vol. 83, no. 3-4, pp. 305-315, 1998.

[21] S. Dash, S. Patel, and B. K. Mishra, "Oxidation by permanganate: synthetic and mechanistic aspects," Tetrahedron, vol. 65, no. 4, pp. 707-739, 2009.
[22] L. Wang, J. Chen, H. Zhang, M. Li, L. Zhang, and S. Liu, "Adsorption performance of semi-coke modified by $\mathrm{KMnO}_{4}$ solution for gas-phase $\mathrm{Hg}^{0}$ in flue gas," Journal of Fuel Chemistry and Technology, vol. 40, no. 12, pp. 1498-1504, 2012.

[23] H. Zeng, F. Jin, and J. Guo, "Removal of elemental mercury from coal combustion flue gas by chloride-impregnated activated carbon," Fuel, vol. 83, no. 1, pp. 143-146, 2004.

[24] S. Eswaran, H. G. Stenger, and Z. Fan, "Gas-phase mercury adsorption rate studies," Energy and Fuels, vol. 21, no. 2, pp. 852857, 2007.

[25] F. E. Huggins, G. P. Huffman, and G. E. Dunham, "XAFS examination of mercury sorption on three activated carbons," Energy and Fuels, vol. 13, no. 1, pp. 114-121, 1999. 

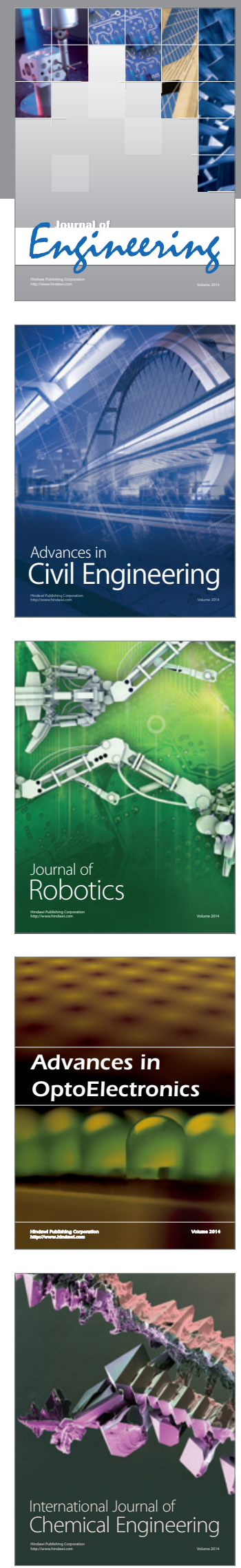

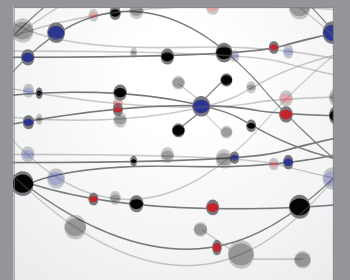

The Scientific World Journal
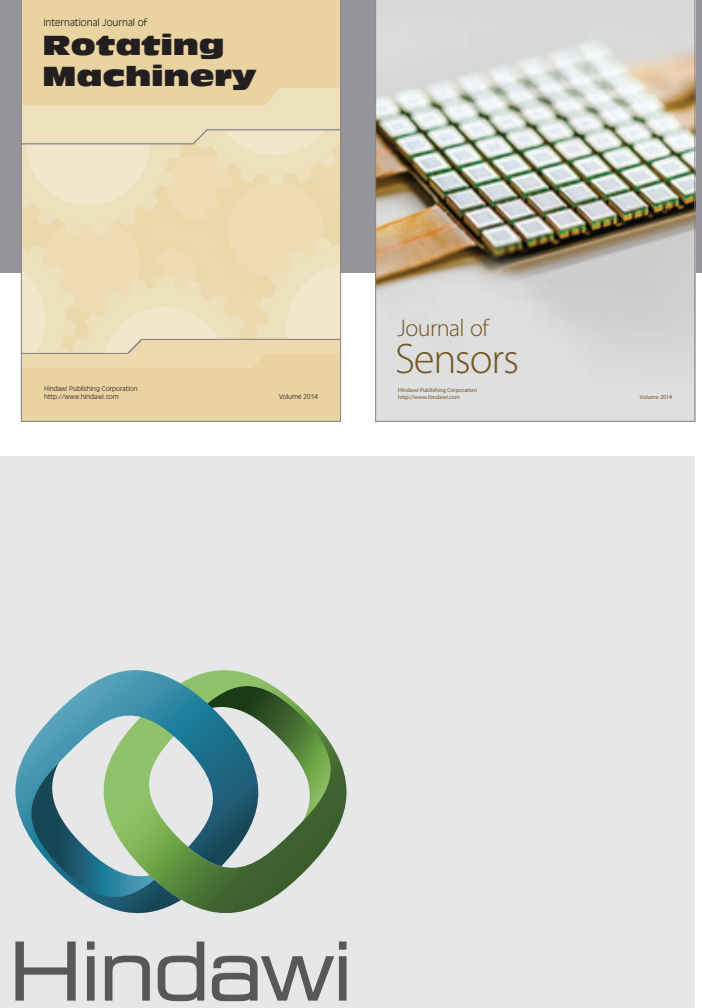

Submit your manuscripts at http://www.hindawi.com
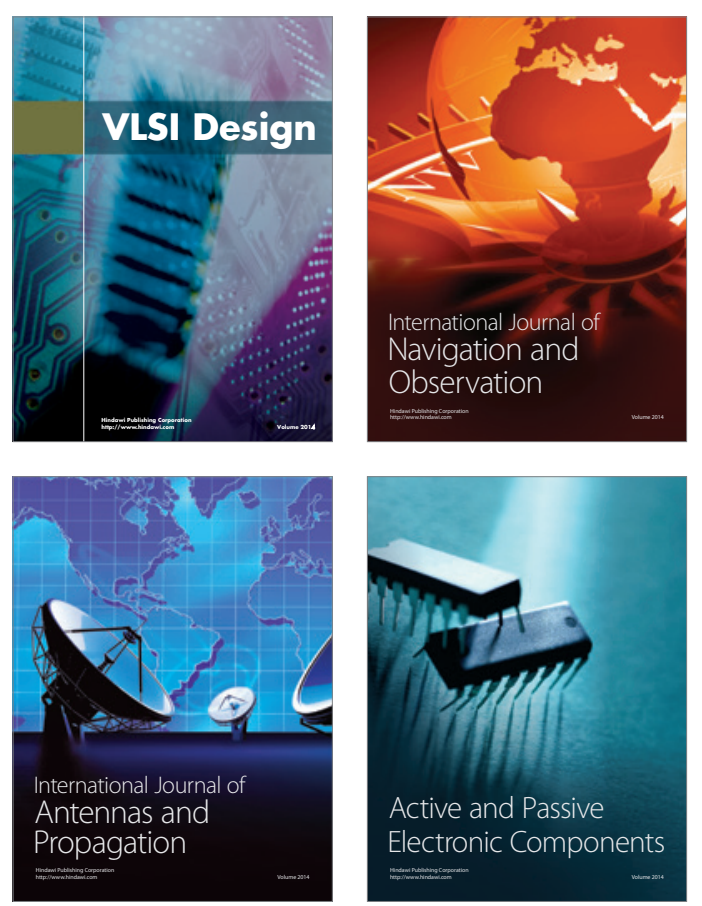
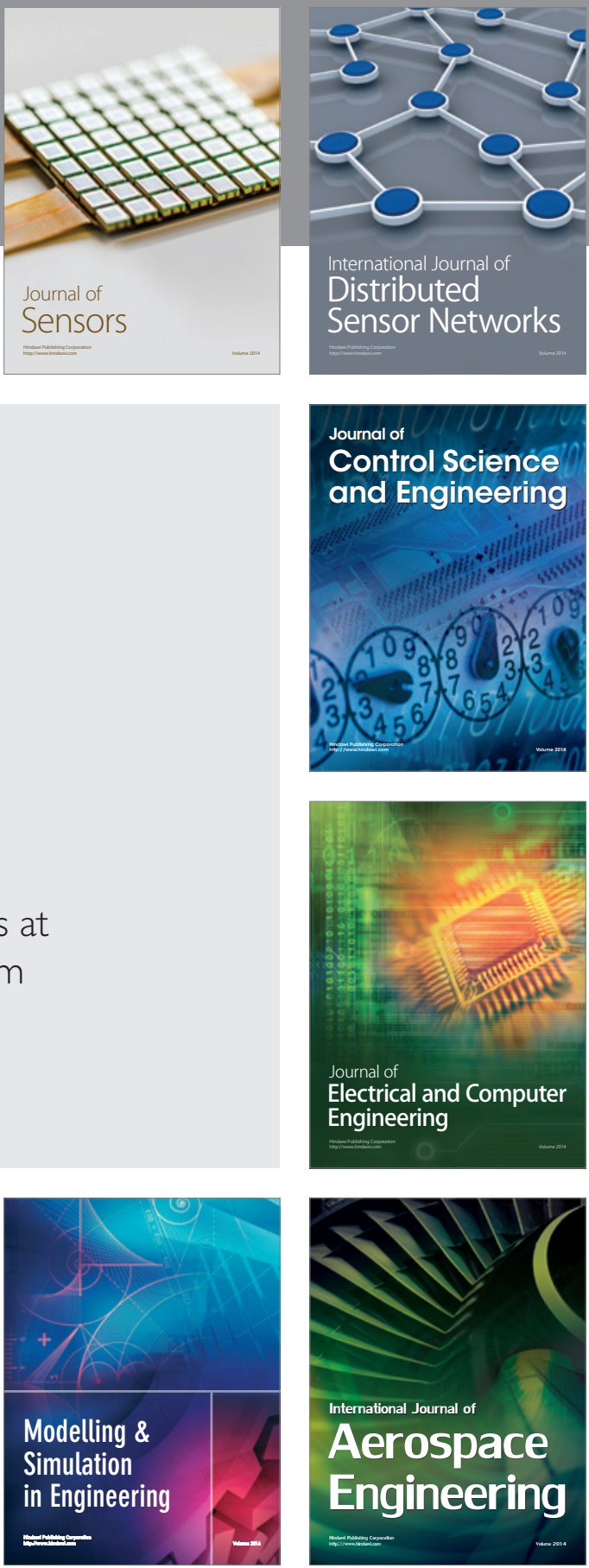

Journal of

Control Science

and Engineering
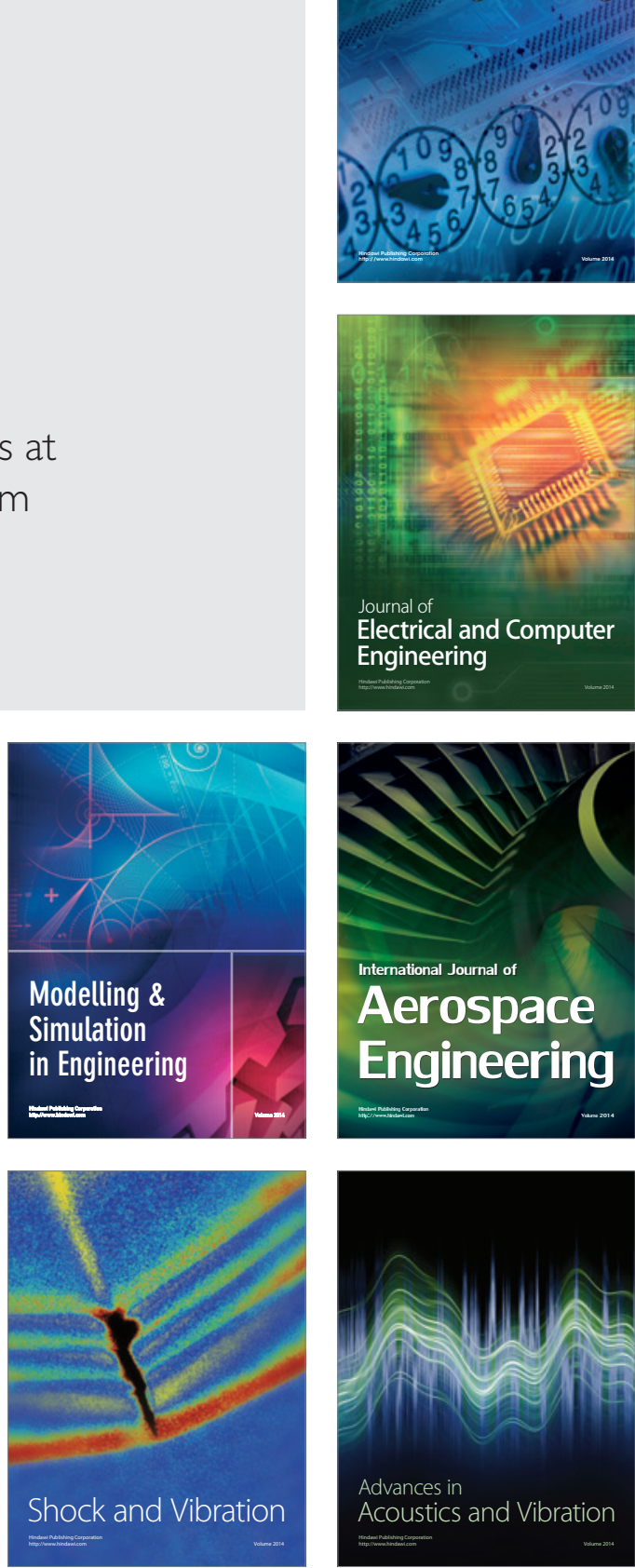